\title{
Correction: Molecular response prediction in CML: novel ideas?
}

\section{Dominik Wolf ${ }^{1}$ and Sieghart Sopper ${ }^{2}$}

${ }^{1}$ Department of Hematology, Oncology and Rheumatology, Center of Integrated Oncology Cologne Bonn, University Hospital of Bonn, Bonn, Germany

2 Department of Hematology and Oncology, Medical University Innsbruck, Innsbruck, Austria

Published: November 09, 2018

Copyright: Wolf et al. This is an open-access article distributed under the terms of the Creative Commons Attribution License 3.0 (CC BY 3.0), which permits unrestricted use, distribution, and reproduction in any medium, provided the original author and source are credited.

This article has been corrected: The added affiliation information is given below:

2 Department of Hematology and Oncology, Medical University Innsbruck, Innsbruck, Austria

Original article: Oncotarget. 2017; 8:80105-80106. https://doi.org/10.18632/oncotarget.21049 